Int. J. Electrochem. Sci., 16 (2021) Article ID: 210224

International Journal of

ELECTROCHEMICAL

SCIENCE

www.electrochemsci.org

\title{
Corrosion Behavior of High Strength C71500 Cu-Ni Alloy Pipe in Simulated High Sulfide Polluted Seawater at Different Temperatures
}

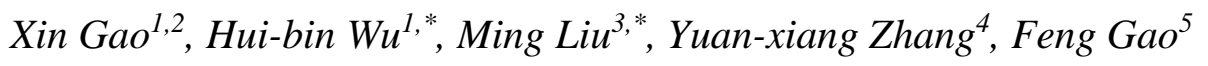 \\ ${ }^{1}$ Institute of Engineering Technology, University of Science and Technology Beijing, Beijing 100083, \\ China \\ ${ }^{2}$ General Research Institute of Nonferrous Metals, Beijing 100088, China \\ ${ }^{3}$ State Key Laboratory for Strength and Vibration of Mechanical Structures, Xi'an Jiaotong University, \\ Xi'an 710049, China \\ ${ }^{4}$ The State Key Lab of Rolling and Automation, Northeastern University, Shenyang 110819, China \\ ${ }^{5}$ School of Materials Science And Engineering, Harbin Institute of Technology, Harbin, 150001, \\ China \\ *E-mail: whbustb@163.com, liuming0313@xjtu.edu.cn
}

doi: $10.20964 / 2021.02 .35$

Received: 4 September 2020 / Accepted: 11 October 2020 / Published: 31 December 2020

\begin{abstract}
By studying the corrosion behavior of high strength $\mathrm{C} 71500 \mathrm{Cu}-\mathrm{Ni}$ alloy pipe at the inlet and outlet of heat exchanger in simulated high polluted seawater at different temperatures, which could provide theoretical basis for improving the service life of the alloy. The corrosion mechanism of the alloy was determined by electrochemical techniques such as potentiodynamic polarization curve, electrochemical impedance spectroscopy (EIS) as well as cyclic voltammetry curve (CV) and the morphology and composition of corrosion products were analyzed by immersion test, SEM, EDS, XPS and XRD. The results show that the alloy exhibits activation polarization at all test conditions, the higher the solution temperature, the greater the corrosion rate. When the temperature reaches $35^{\circ} \mathrm{C}$, the average corrosion rate of the alloy is stable at about $0.0121 \mathrm{~mm} / \mathrm{a}$. In the initial stage of corrosion, diffusion process could be observed. Corrosion products have a certain protective effect, the diffusion process disappears and the EIS shows only capacitive reactance arc with the prolong the immersion time. The addition of high concentration of $\mathrm{Na}_{2} \mathrm{~S}$ promotes the formation of $\mathrm{Cu}_{2} \mathrm{~S}$ and the redox process, thus accelerating the corrosion process. At relatively low temperature, the dominant process is Ni dissolution, while the content of $\mathrm{Cu}$ and $\mathrm{S}$ dissolving increase at high temperature. The thickness and compactness of corrosion products increase with the increasing temperature, which promotes to reach a relative stable corrosion rate. More sulfide species corrosion product could be detected at the low temperature, and the dissolution of copper is the main corrosion process at high temperature.
\end{abstract}

Keywords: C71500 Cu-Ni pipe; sulfide polluted; temperature; corrosion behavior; seawater 


\section{FULL TEXT}

(C) 2021 The Authors. Published by ESG (www.electrochemsci.org). This article is an open access article distributed under the terms and conditions of the Creative Commons Attribution license (http://creativecommons.org/licenses/by/4.0/). 